Published as: Andersson, H., and M. Ögren: 2011, 'Noise Charges in Road Infrastructure: A Pricing Schedule Based on the Marginal Cost Principle'. J ournal of Transportation

Engineering 137(12), 926\{933.

\title{
Noise Charges in Road Traffic: A Pricing Schedule Based on the Marginal Cost Principle
}

\author{
Henrik Andersson $^{1} \quad$ Mikael Ögren $^{2}$
}

Keywords: externalities, marginal cost, noise, road traffic

\section{Abstract}

One way of mitigating the negative effects of noise from road traffic is to include the external cost of noise in a road charging system. This study shows how standardized calculation methods for road traffic noise can be used together with monetary estimates of the social cost of noise exposure to calculate charges based on the social marginal cost. Using Swedish data on traffic volume and individuals exposed to road noise, together with official Swedish monetary values for noise exposure, we estimate road-noise charges for cars and heavy vehicles.

\section{INTRODUCTION}

An environmental problem of growing importance is noise emissions from traffic. Noise exposure is not only a disutility in the sense that it disturbs people, it can also result in health impairments and lost productivity and leisure. The reason why the problem is growing is a combined effect from urbanization and an increase in traffic volume. Whereas the increase in traffic volume means higher noise levels, the urbanization has led to more individuals being exposed to traffic noise. These trends are likely to continue, and hence unless efforts are taken to mitigate the problem, it will increase as a result of more people being exposed to higher noise levels in the future (Nijland et al. 2003).

As a mean to mitigate this and other environmental and health problems related to transportation, the European Union (EU) has decided that infrastructure charges in the EU should be based on short-run marginal costs (SRMC) (European Commission 1998). Policy makers can choose between reducing either the emission or the exposure, and noise charges based on SRMC give road users incentives to reduce their emissions, since those operators who contribute more to the noise emissions will have to pay more to use the infrastructure. Since infrastructure charges based on SRMC internalize not only the external effects on the rest of the society, but also within the transport sector, charges based on SRMC that fully reflect social costs have the potential to result in

\footnotetext{
${ }^{1}$ Toulouse School of Economics (LERNA, UT1, CNRS), henrik.andersson@tse-fr.eu

${ }^{2}$ Corresponding author, VTI, Box 8077, SE-402 72 Gothenburg, mikael.ogren@vti.se
} 
an optimal traffic volume and use of technology. Several studies have also shown that the costs of reducing emission at the source are lower than the costs of reducing high noise levels through barriers, façade insulation, etc. (Oertli 2000; de Vos 2003). Following Andersson and Ögren (2007), regarding the conflict between the marginal social cost principle, and long-run incremental costs and full cost recovery, we refer to other literature for discussions on charging principles or financing problems, e.g. Nash (2005), Rothengatter (2003), or Sansom et al. (2001).

In a previous study Andersson and Ögren (2007) outlined a model on how to estimate noise charges for railway infrastructure based on SRMC. They showed that already obtained knowledge on monetary and acoustical noise evaluation could be used to estimate the charges. In this study we extend the analysis in Andersson and Ögren (2007) and the aim of this study is to describe how road-noise charges based on the marginal cost principle can be estimated. The challenge of developing a model to estimate noise charges for road compared with rail traffic is the multiple noise sources we have to consider. Whereas it is reasonable to assume that individuals living in a certain area are only exposed to rail noise from a single railway track, it is necessary to take into consideration that several different noise emission sources (roads) can contribute to the noise exposure when the marginal acoustical effect is estimated for road noise. Since it has been decided that charges shall be implemented and based on the SRMC principle in order to internalize noise it is important to design a model that calculates the SRMC on vehicle level, something the model in this study is capable of.

The paper is organized as follows. In the section below we briefly describe the SRMC in terms of an increase in road traffic. In later sections we briefly discuss noise and how it is measured, before we describe how to estimate the marginal acoustical effect from road traffic. Then we present a case study from Sweden where we estimate road-noise charges for passenger cars and trucks and examine the sensitivity of our results to traffic volume and number of exposed individuals. Finally we offer some conclusions regarding our model and the results.

\section{THE MARGINAL SOCIAL COST AND ROAD-NOISE CHARGES}

The SRMC of being exposed to road noise is the social cost of one extra vehicle. Following Andersson and Ögren (2007), let $C(L(Q, r, X))$ denote the individual costfunction which is a function of the noise level $L$. The noise level is assumed to be determined by the traffic volume $(Q)$, distance to the noise emission source $(r)$, and a vector of other factors assumed to influence the noise level $(X)$, e.g. traffic composition, presence of barriers, meteorological effects and ground properties. The total social noise cost of road traffic $(S)$ can then be estimated as

$$
S=\int_{0}^{\infty} C(L(Q, r, X)) n(r) \mathrm{d} r
$$

where $n(r)$ is the density of exposed individuals at different distances. The marginal social cost $(M)$ is the change in total cost as a result of a change in traffic volume, i.e.

$$
M=\frac{\partial S}{\partial Q}=\int_{0}^{\infty} \frac{\partial C(L(\cdot))}{\partial L} \frac{\partial L(\cdot)}{\partial Q} n(r) \mathrm{d} r .
$$


However, as explained in Andersson and Ögren (2007), data on distributions of individuals and noise levels (constant within a specific interval) are often available in discrete and not continuous forms. The estimation of noise charges is then carried out using discrete models and $M$ can be written as

$$
M=\sum_{i} c(L(\cdot)) n(r) \Delta r \frac{\partial L(\cdot)}{\partial Q},
$$

where $i$ refers to each discrete interval and $c(L(\cdot))=\partial C(L(\cdot)) / \partial L$.

The marginal social cost in equation (3) can be seen as the total cost change for a unity change in traffic volume $\Delta Q=1$. The change in noise level $\Delta L$ that the marginal vehicle causes can then be expressed as

$$
\Delta L=\partial L(\cdot) / \partial Q
$$

The number of exposed to the noise level $L$ is given by $N(L)$, corresponding to $n(r) \Delta r$ in equation (3). Finally equation (5) is the road-noise charge estimated in this paper,

$$
T=\sum_{L} c(L(\cdot)) N(L) \Delta L
$$

\section{ACOUSTICAL PARAMETERS}

\section{Noise Indicator}

The strength of noise is measured using the sound pressure level (SPL) in $\mathrm{dB}$. This level is normally A-weighted to account for the average sensitivity of the human ear to different frequencies. Noise exposure is commonly expressed as an equivalent level, which is an energy average over a certain time period, or as the maximum level during the time period. More details on measurement and description of road traffic noise can be found in Sandberg and Ejsmont (2002).

The equivalent level is normally used as an indicator of general annoyance, and the maximum level as an indicator of sleep disturbance. The maximum level is also less suitable for SRMC calculations since it is only influenced by the loudest vehicle (or loudest combination of several simultaneously audible vehicles at longer ranges), all other vehicles have no influence at all. The equivalent level on the other hand has a clear relation to traffic volume, and for each extra vehicle added to the traffic along a road the equivalent level increases.

The equivalent level for a full 24-hour period is denoted $L_{\mathrm{AEq}, 24 \mathrm{~h}}$, which is the most commonly used noise indicator. In the Environmental Noise Directive (European Commission 2002) another indicator, the $L_{\text {den }}$ (level day evening night), is chosen as the noise indicator to be used in the future for road traffic noise in the EU. It is an equivalent level with a penalty for traffic that occurs at evening or night time, and can be calculated from the equivalent noise level during the day $\left(L_{d}\right)$, evening $\left(L_{e}\right)$ and night $\left(L_{n}\right)$ using

$$
L_{d e n}=10 \log \left(\frac{12}{24} 10^{0.1 L_{d}}+\frac{4}{24} 10^{0.1\left(L_{e}+5\right)}+\frac{8}{24} 10^{0.1\left(L_{n}+10\right)}\right) .
$$


Using this indicator the marginal noise contribution of a single vehicle passage is larger at evening and night time, which means that the marginal cost depends on the time the passage occurs.

\section{Calculating the Acoustical Marginal Effect}

The marginal effect in acoustical terms $(\Delta L)$ is the effect one extra vehicle will have on the noise level. This is determined not only by the acoustical parameters of the extra vehicle, but also by the total traffic already on the road. The change in the equivalent sound level can be very small. For a traffic volume of 20,000 vehicles per day one extra light vehicle will only increase the sound level by about $0.0002 \mathrm{~dB}$.

The increase in the level a single vehicle will cause can be calculated using standardized and well established calculation methods. There are a large number of national methods in use (Nijland and Van Wee 2005), but there is also a common European method called Harmonoise (de Vos et al. 2005). This is a new method that take recent developments in the field of outdoor sound propagation into account. Harmonoise was developed in order to gradually replace national methods in the EU as required by the Environmental Noise Directive (European Commission 2002).

Calculating the increase due to one vehicle is then simply a matter of calculating the difference between the noise emitted from the traffic before and after adding the marginal vehicle. This assumes that the vehicle is representative for its class, since the calculation methods calculate the noise from a stream of typical vehicles. If instead individual data is know, for example as a result of introducing low noise technology such as less noisy tires on a specific vehicle, the calculation procedure becomes slightly more complex (the details are omitted here).

If the equivalent sound level is increased by, for instance, $1 \mathrm{~dB}$ at a distance of $20 \mathrm{~m}$ from the road, the same increase is valid for longer ranges. This is not exactly true, but it is a good approximation for most cases where no extreme shielding is present and the noise from the vehicles do not contain strong tonal components. An example calculation using Harmonoise for ranges up to $200 \mathrm{~m}$ for flat terrain and optionally including a $3 \mathrm{~m}$ high screen is given in Table 1. The calculation is based on the Harmonoise engineering method (Nota et al. 2005), which has many parameters. Default values were chosen for temperature, relative humidity, source heights, atmospheric pressure, density and turbulence. The flow resistivity of the ground was set to $200 \mathrm{kNsm}^{-4}$ (corresponding to a normal pasture field). No wind and temperature refraction effects were included. The source strengths were set to the total traffic given assuming a traffic mix of $10 \%$ heavy vehicles (class $3 \mathrm{c}$ ), with a receiver height of $2 \mathrm{~m}$ and an optional $3 \mathrm{~m}$ high sound screen $6 \mathrm{~m}$ from the source.

That the change in noise level is not depending on distance simplifies the calculation of the marginal change, but still the total noise level must be calculated for the total traffic in all interesting receiver positions in order to calculate the monetary effect. Note that this assumes that only one source is contributing to the total noise level, which is normally true for rail traffic noise but not always for road traffic noise, as discussed in the next section. 
Table 1. Marginal change in noise level as a function of distance

\begin{tabular}{llrrrr}
\hline & Traffic & $20 \mathrm{~m}$ & $50 \mathrm{~m}$ & $100 \mathrm{~m}$ & $200 \mathrm{~m}$ \\
\hline Flat & 20,000 & 66.9 & 56.6 & 49.0 & 43.2 \\
ground & 16,000 & 65.9 & 55.6 & 48.0 & 42.2 \\
& Diff. & 1.0 & 1.0 & 1.0 & 1.0 \\
\hline Screening & 20,000 & 53.1 & 50.3 & 46.9 & 43.5 \\
& 16,000 & 52.1 & 49.4 & 45.9 & 42.6 \\
& Diff. & 1.0 & 0.9 & 1.0 & 0.9 \\
\hline
\end{tabular}

\section{Effect of secondary sources}

Noise from railways usually occur in loud train passages with silent periods in between. Road noise is often a more constant noise except for roads with very low traffic volumes or in the middle of the night. The positive aspect of road noise compared to railway noise is that the maximum peaks are typically much lower, and the positive aspect for the railway is the silent periods that occur in between events. Another important difference is that railway noise has the most energy at slightly higher frequencies than road traffic noise, which is important for indoor levels since the façade insulation is dependent on the frequency. However, in this study only outdoor levels are considered.

One important difference between how railway and road traffic noise are handled, is that when calculating the noise at a building façade from railway traffic normally only one railway line contributes to the level. For road traffic noise all roads in the vicinity are normally taken into account. This is obviously the correct approach when studying the total noise exposure for inhabitants, e.g. when planning noise reducing measures in an residential area. But when calculating the SRMC of using a road and there are secondary roads in the area it is not straightforward how to proceed.

Consider calculating the SRMC for noise from a major road through a small city. At certain positions in the city, e.g. where the noise from the major road is well shielded by buildings, the contribution from the traffic on the small streets will dominate and a change of the traffic volume on the major road will have a negligible effect on the sound level, and thus a negligible effect on the marginal cost. Hence, assuming that the marginal sound change is the same for all receiver positions will overestimate the marginal cost unless only a single source dominates the level throughout the area to be studied.

This effect is illustrated in Fig. 1, where the noise is displayed as contours of equal noise level for a simple flat landscape with one primary and one secondary road with less traffic. If we increase the traffic at the primary road the sound level at position $A$ will increase (as illustrated by the moving of the contour line), but at position $B$ it will hardly increase at all. Therefore it is important to calculate the marginal change including the effects of secondary sources for receiver positions where both the main and secondary roads give a substantial contribution to the sound level. 
Figure 1. Illustration of a main road which is crossed by a smaller road and the effect on the noise level contours when the traffic is increased on the main road.

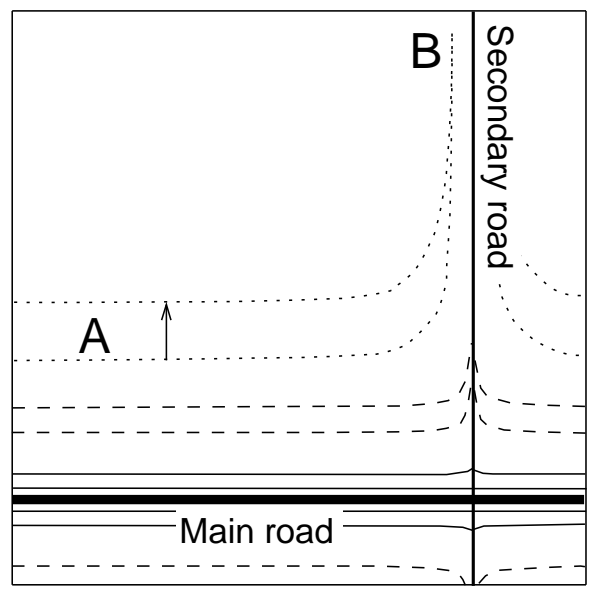

\section{CASE STUDY LERUM}

In 2004 Öhrström et al. (2005) conducted a study in Lerum, a municipality close to Gothenburg in Sweden with about 36,000 inhabitants and a population density of 146 inhabitants per $\mathrm{km}^{2}$. The aim of the study was to determine health effects and annoyance both for railway and road traffic noise, and also to look for combined effects when exposed to both sources. Öhrström et al. (2005) did not analyze the social cost or the marginal social cost from traffic noise, instead we use their data to conduct such an analysis of the social marginal cost.

Two major transport routes cross the municipality, the railway line Västra stambanan and the motorway E20. Both connect Gothenburg and Stockholm. (Öhrström et al.) selected a subset of the municipality for detailed noise calculations and a questionnaire survey, see the sketch in Fig. 2. In this study we use the noise calculations from this survey to estimate the noise levels behind the SRMC.

Note that only the calculated levels from road traffic are used here. One might argue that if a certain building is exposed to high levels from railway traffic the effect of the road traffic is masked and should be set to zero, but there is in fact evidence for that the annoyance caused by the lesser source is more pronounced when another source is present (Öhrström et al. 2005). In principle the combination of the sources cancels the good aspect of each source as explained previously, i.e. no more silent periods/absence of loud peaks. This means that in cases were more than one source is present the monetary effect is underestimated for both sources, as is the case in Lerum.

\section{The Monetary Values used in our Case Study}

Since the aim of this study is not to elicit preferences for noise abatement, but to outline a model for road noise charges, we do not estimate any monetary values for noise reductions. Instead we use the official monetary values used in Sweden for benefit-cost analysis (BCA) within the transport sector (Friberg et al. 2008). These values are based on the results of a Swedish hedonic property-value study (Wilhelmsson 
Figure 2. Sketched map over the research area.

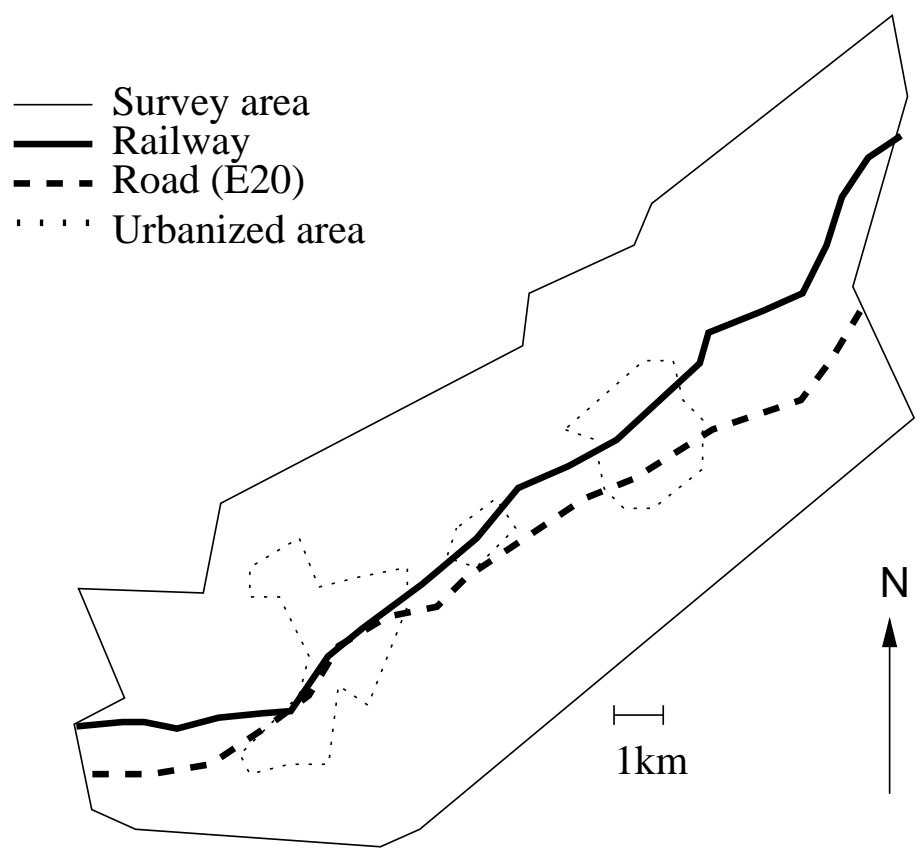

1997), which examined relationship between property values and exposure to noise from road traffic in a suburb of Stockholm, Sweden. However, it was assumed that values from the hedonic study did not reflect the total social cost and the values were therefore increased by $42 \%$ to also reflect health costs

We use the official monetary values since this is the most likely approach for national agencies to adopt when the SRMC pricing scheme will be implemented. It is well known that preferences for reducing noise levels are context dependent, and therefore, the values used in this study may not be representative for other countries. This is, however, not problematic for the aim of this paper, since we are describing a method to calculate noise charges and the difference in monetary values will only change the level of the noise charges. For other studies on the evaluation of noise abatement, see e.g. Day et al. (2007), Navrud (2004) and Nelson (2004).

The official cost estimates for Sweden are only available in table format (Friberg et al. 2008), but can be approximated with the following function

$$
c(L)=540.3 \frac{0.6634 e^{0.6634 L-44.6}+0.05569 e^{0.05569 L-2.798}}{e^{0.6634 L-44.6}+e^{0.05569 L-2.798}}
$$

where $L=L_{\mathrm{AEq}, 24 \mathrm{~h}}, L_{\mathrm{AEq}, 24 \mathrm{~h}} \in[50,75] . L_{\mathrm{AEq}, 24 \mathrm{~h}}$ refers to the equivalent A-weighted noise level in $\mathrm{dB}$. Monetary values are in Euros (€) in 2006 price level and represent the marginal cost, i.e. the yearly cost for a $1 \mathrm{~dB}$ increase in noise level per person. The lower bound equals $50 \mathrm{~dB}$ since people are assumed not be annoyed at levels below this level, hence, there is no social cost from noise levels below $50 \mathrm{~dB}$ (Friberg et al. 2008). The upper bound does not apply in our analysis since no individuals in the case study area are exposed to noise levels above $75 \mathrm{~dB}$. 


\section{Marginal Acoustical Effect}

The marginal acoustical effects of different vehicle types are calculated using the harmonized European method called Harmonoise (de Vos et al. 2005). The main advantage of using Harmonoise in this study is that it can calculate source strengths for many different vehicle classes, whereas the older Nordic method (Jonasson and Nielsen 1996) only differentiates between light and heavy vehicles. The basic vehicle classes are numbered from 1 to 5, and are light vehicles (1), medium heavy vehicles (2), heavy vehicles (3), other heavy vehicles (4) and two wheelers (5). There are also subclasses denoted by a lower case letter that differentiate between number of axles, general vehicle type and so on. The classes selected for calculation in our case are presented in Table 2.

\section{Traffic Volume and Number of Exposed Individuals}

The traffic on the motorway E20 varies from 16,500 vehicles per 24 hours at the east border of the research area to about 21,700 at the west border. The percentage of heavy traffic is approximately $9 \%$ (vehicles of class 2 and 3 using the Harmonoise terminology).

The number of exposed individuals is determined from the data collected in the study mentioned above (Öhrström et al. 2005). In the research area 3,120 dwellings had $L_{\mathrm{AEq}, 24 \mathrm{~h}}$ higher than $45 \mathrm{~dB}$, and 2,751 questionnaires were distributed with a return rate of $71 \%$, i.e. 1,953 households answered the survey. The total number of exposed in our study is estimated based on the respondents' answers about household size and the total number of exposed dwellings, and the average number of inhabitants per dwelling were 2.8 .

A set of calculations of $L_{\mathrm{AEq}, 24 \mathrm{~h}}$ and $L_{\mathrm{den}}$ noise levels for both rail and road traffic noise were carried out for those who answered the questionnaire, and it is only the road traffic noise values that are used in this study. The sound levels were determined using the Nordic method (Jonasson and Nielsen 1996). Non-responding households are excluded from our analysis since less information on noise exposure is available for them, and the number of exposed is, thus, underestimated.

As explained above it is important to separate the effect of the primary road and other small roads in the calculations when determining the SRMC. In the calculations available for Lerum all sources are summed up and there is no information of each roads relative contribution to the total level, and it is outside the scope of this study to redo the calculations for all receiver points to obtain this information. Instead we identify and remove households whose main noise source is a secondary road, which again leads to an underestimation of the SRMC.

Removing households significantly exposed to secondary roads is achieved by plotting the equivalent sound level versus the distance to the main road in Fig. 3. Using the Nordic method for road traffic noise we calculate what the level should be at different distances in a perfectly flat landscape and plot this line together with the data for all households. The Nordic method is accurate up to $300 \mathrm{~m}$ only, but is extended here to longer ranges. The resulting line is an average over two calculations, one for acosutically soft and one for acoustically hard ground. 
Figure 3. Scatter plot of calculated sound levels vs the distance to the main road. Points indicated by $\times$ are considered to be exposed only to the main road (90\%), and + are considered to be exposed only to secondary roads (10\%).

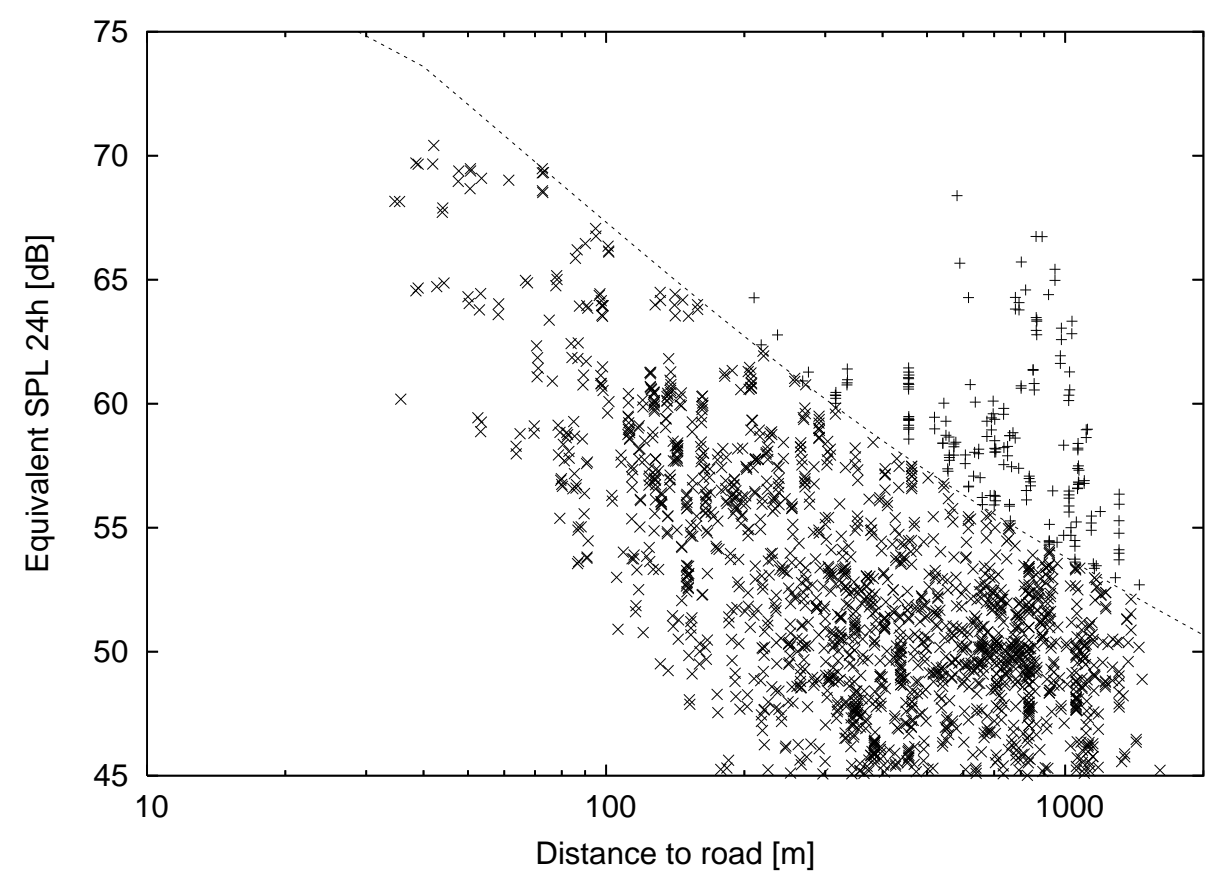

In reality houses are hardly more exposed than in the flat case, but may well be less exposed if they are screened by barriers, terrain or buildings. Therefore all points that lie above the calculated line represent a household significantly exposed to other roads, and are removed from further analysis.

Fig. 4 shows the number of exposed inhabitants in each $1 \mathrm{~dB}$ interval. The number of inhabitants removed as discussed above is also illustrated, which corresponds to $10 \%$ of the total number of inhabitants.

\section{Estimation of Road-Noise Charges for Lerum}

By combining information about the marginal cost function and the number of individuals exposed at different noise levels, the social cost associated with a marginal increase in the noise level can be estimated. Using the marginal change in sound level, the annual marginal cost $(T)$ in the survey area is calculated by multiplying the number of inhabitants in a $1 \mathrm{~dB}$ interval with the cost function and the acoustical change,

$$
T=\sum_{L=50}^{75} c(L) N(L) \Delta L,
$$

where $L$ defines $L_{\mathrm{AEq}, 24 \mathrm{~h}}$, and $N(L), c(L)$ and $\Delta L$ are the number of inhabitants exposed in the $1 \mathrm{~dB}$ interval centered around $L$, the annual cost function from equation (7) and the change in sound level due to the marginal vehicle, respectively.

Fig. 5 shows how the contribution to the marginal cost from one extra vehicle varies with $L_{\mathrm{AEq}, 24 \mathrm{~h}}$. Levels below $50 \mathrm{~dB}$ do not contribute at all since the cost function is 
Figure 4. Histogram of number of inhabitants in each $1 \mathrm{~dB}$ interval showing the effect of removing the influence of secondary roads.

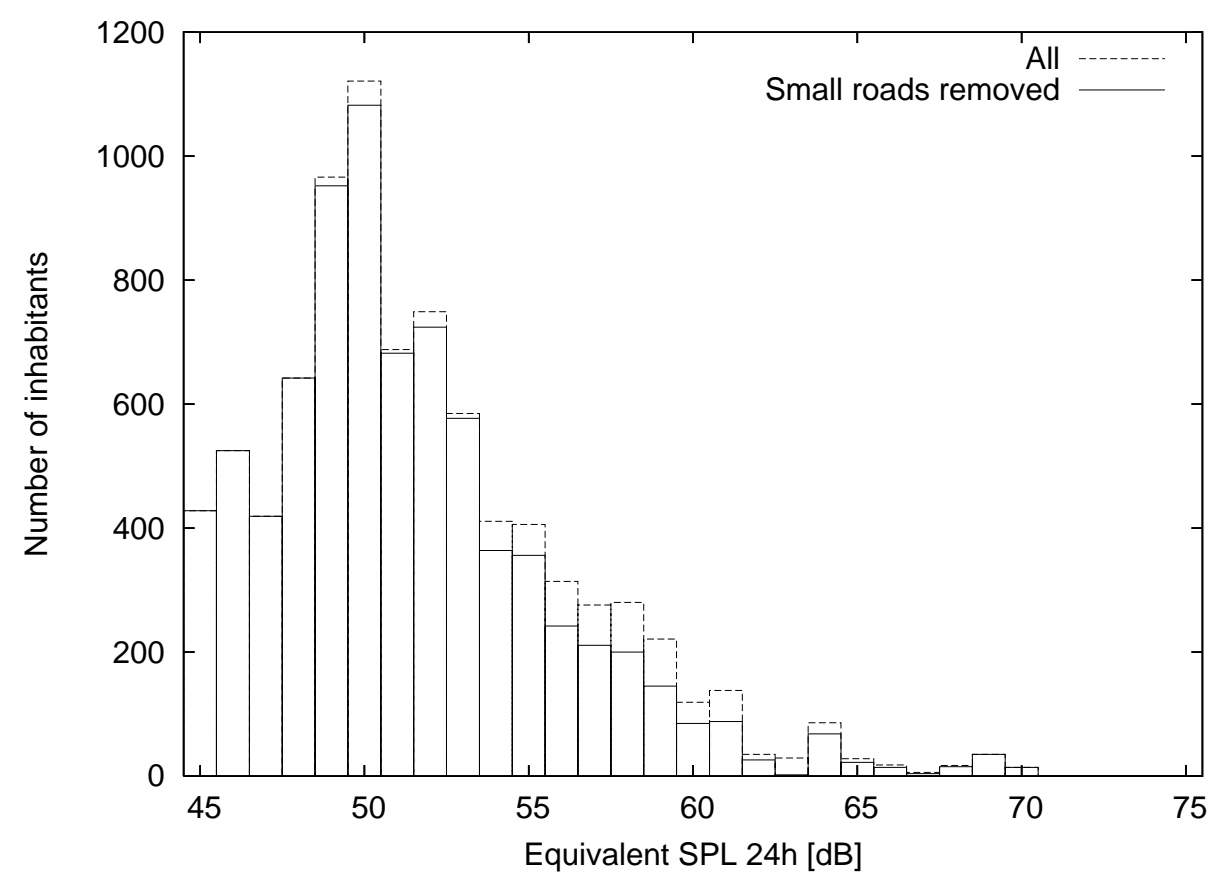

not defined below $50 \mathrm{~dB}$. It is interesting to note that even though the marginal cost per inhabitant is substantially lower for the inhabitants at the lower noise levels, their contribution is important since there are many more inhabitants at lower levels. For instance, inhabitants exposed to levels below $55 \mathrm{~dB}$ (a level often considered to be tolerable (Nijland and Van Wee 2005)) account for $63 \%$ of the total marginal cost. In Andersson and Ögren (2007) inhabitants below $55 \mathrm{~dB}$ accounted for $32 \%$ of the total marginal cost for railway traffic.

For a charging scheme to be fair and efficient, charges should be based on distance covered by the vehicle (European Commission 2001). To get the calculated total marginal cost for the survey area in $€ / \mathrm{km}$ it must be adjusted by the number of days per year and the length of the distance travelled for our examined vehicle(s) $(17 \mathrm{~km})$. The marginal cost estimates per $\mathrm{km}$ for a representative subset of vehicle classes is presented in Table 2. Based on a 10\% increase in traffic, Sansom et al. (2001) estimated, for Great Britain, SRMC for cars and trucks in the ranges 0.00017-0.0087 and 0.0010$0.072 € / \mathrm{km}$. These values were originally presented in GBP 1998 price level, but have been adjusted using consumer price indices and exchange rates (www.econstats.com, 06/07/06).

As discussed above the SRMC will depend on the time of the passage if the noise indicator $L_{\mathrm{den}}$ is used since it introduces a penalty for evening and night time traffic. If the normal equivalent level $L_{\mathrm{AEq}, 24 \mathrm{~h}}$ is used then it does not matter at which time the vehicle passage occurs. Note that using $L_{\text {den }}$ gives a lower daytime cost than using $L_{\mathrm{AEq}, 24 \mathrm{~h}}$, but the evening and night time costs are higher. The cost function in equation (7) is based on the equivalent level, which may introduce errors when calculating 
Figure 5. Histogram of the contribution to the total SRMC from the inhabitants in each $1 \mathrm{~dB}$ interval.

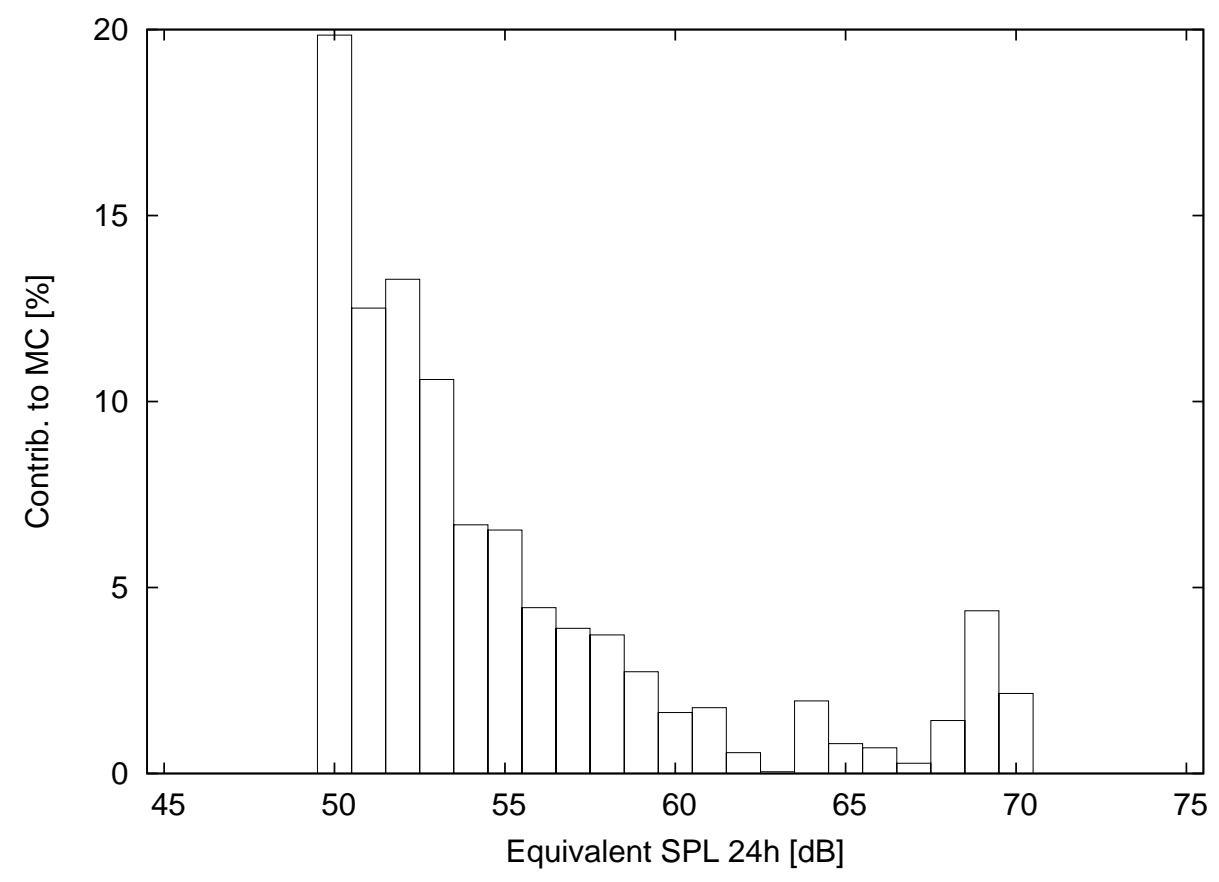

Table 2. Marginal cost in $€ / \mathbf{k m}$

\begin{tabular}{cllll}
\hline & & \multicolumn{3}{c}{ Trucks } \\
\cline { 3 - 5 } & $\begin{array}{l}\text { Cars } \\
\text { Light (1a) }\end{array}$ & $\begin{array}{l}\text { Medium } \\
\text { 3 axles (2c) }\end{array}$ & $\begin{array}{l}\text { Heavy } \\
5 \text { axles (3c) }\end{array}$ & $\begin{array}{l}\text { Heavy } \\
7 \text { axles (3d) }\end{array}$ \\
\hline $\begin{array}{c}L_{\text {AEq,24h }} \\
24 \mathrm{~h}\end{array}$ & 0.0010 & 0.0041 & 0.012 & 0.016 \\
$\begin{array}{c}L_{\text {den }} \\
\text { day }\end{array}$ & 0.00043 & 0.0017 & 0.0049 & 0.0069 \\
evening & 0.0014 & 0.0054 & 0.015 & 0.022 \\
night & 0.0043 & 0.017 & 0.049 & 0.069 \\
\hline
\end{tabular}

Vehicle classification refers to Harmonoise vehicle class:

1a - Cars, 2 axles max 4 wheels

$2 \mathrm{c}$ - Medium heavy trucks, 2 axles (6 wheels)

$3 \mathrm{c}$ - Heavy trucks, $4-5$ axles

$3 \mathrm{~d}$ - Heavy trucks, $\geq 6$ axles 
Figure 6. Marginal cost per $\mathrm{dB}$ and marginal change in the equivalent sound level as a function of the total traffic volume.

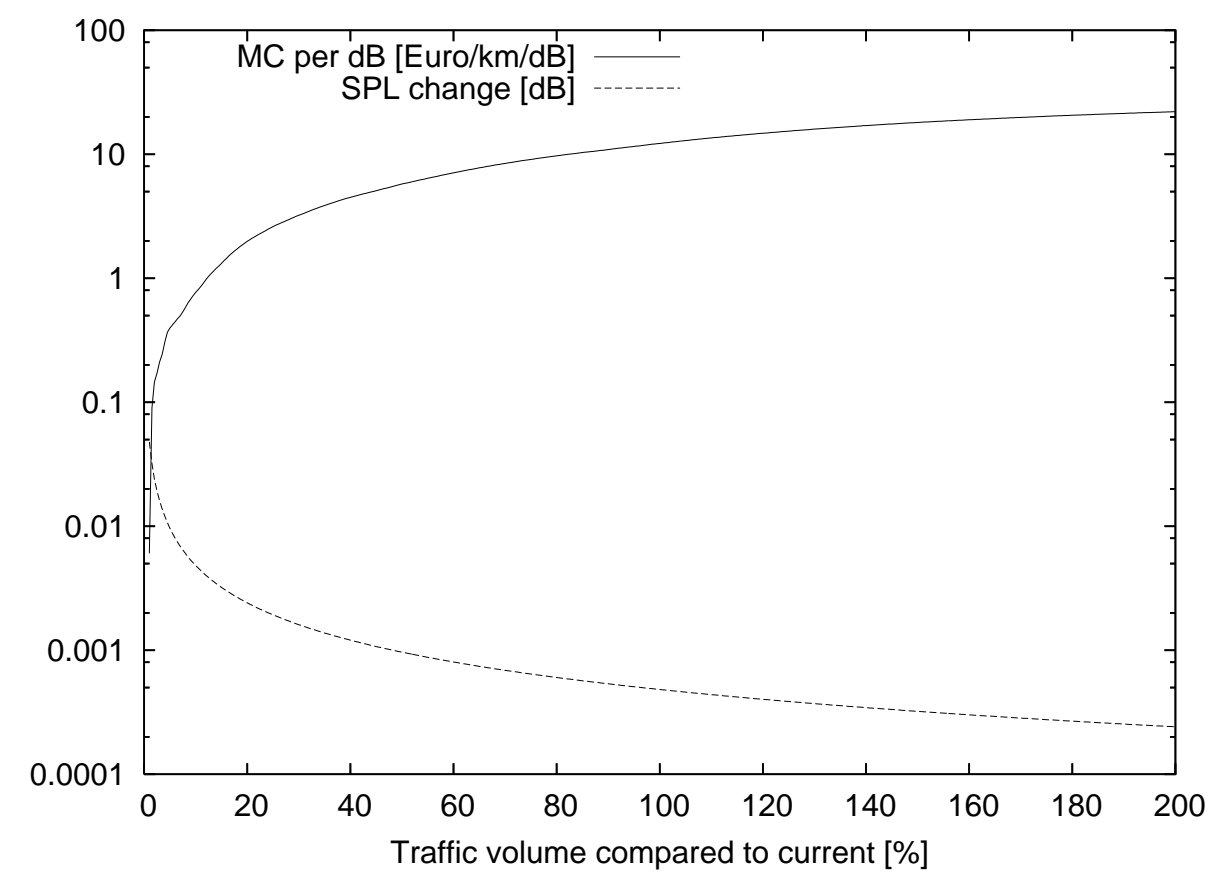

the cost for the level day evening night indicator (Andersson and Ögren 2007).

In Andersson and Ögren (2007) the SRMC was determined for railway traffic through the same research area, and the results are also presented as a cost per $\mathrm{km}$ for different train sets. It is tempting to directly compare the cost for a freight train to that of a truck, but there are two difficulties with this approach. First the number of exposed persons is not the same since the railway line and the road are separated in the landscape. Second, the cost function used in both studies was determined for road noise only, and is either used as it is or is adjusted to railway values using a crude railway bonus of $5 \mathrm{~dB}$ (Andersson and Ögren 2007).

\section{Sensitivity to Total Traffic Volume}

The marginal acoustical effect and the SRMC of a single vehicle passage depends on both the noise source strength of the vehicle and on the traffic already present on the road. Given a certain traffic volume and noise level, the SRMC from a single vehicle is ambiguous, since a high (low) noise level means a high (low) marginal social cost but a small (large) marginal acoustical effect (Andersson and Ögren 2007). To examine how the SRMC is affected by a change in traffic volume we therefore rely on a numerical example. In Fig. 6 the upper curve is the calculated marginal cost for a $1 \mathrm{~dB}$ change in sound level and the lower curve the change in sound level a single vehicle passage will cause. Note that the y-axis is logarithmic, and $100 \%$ corresponds to the traffic used in the case study (approximately 20,000 vehicles per $24 \mathrm{~h}$ ). The vehicle used for the example is a heavy truck with 5 axles (class $3 \mathrm{c}$ using Harmonoise terminology).

In Fig. 7 the SRMC, which is the product of the two effects from Fig. 6, is cal- 
Figure 7. Marginal cost expressed as $€ / \mathrm{km}$ through the research area for a class $3 \mathrm{c}$ vehicle as a function of the total traffic volume.

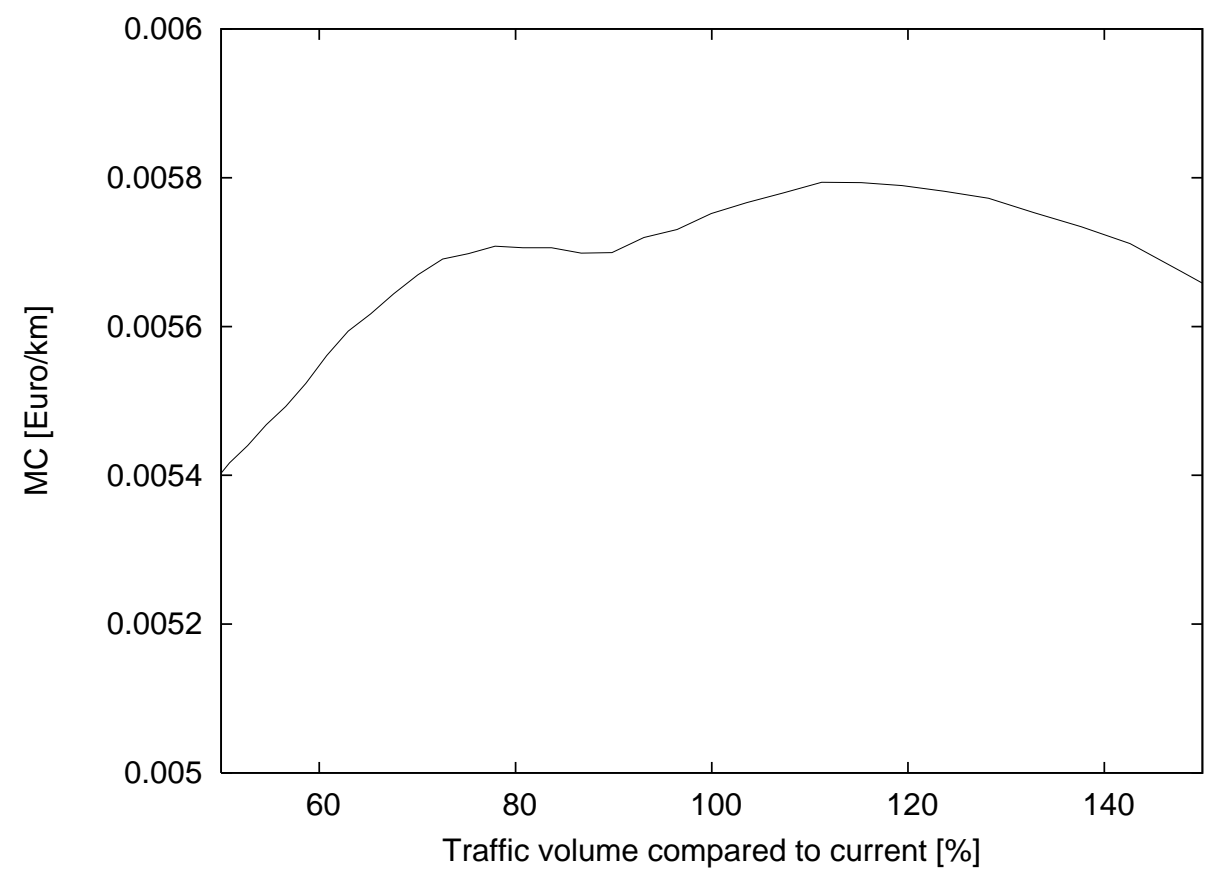

culated as a function of total traffic volume. Note that both of the effects are strictly increasing/decreasing, but their product is not. Between $50 \%$ and $150 \%$ traffic the curve is more or less constant $( \pm 4 \%)$, which means that the estimated marginal costs are rather robust even if the traffic is changed. This insensitivity to traffic volume was also found for rail traffic in Andersson and Ögren (2007).

As the source strength increases individuals are shifted from low noise levels and up to higher, but no new individuals enter at low levels due to the limited size of the research area. Therefore the area is too small to accurately estimate the effect at traffic volumes higher than $150 \%$, and a slight drop off can be noted already above $120 \%$.

\section{Sensitivity to the Number of Individuals Exposed to Noise}

As illustrated in Fig. 7, the SRMC is insensitive to changes in the total traffic volume. Changing the number exposed has a large influence though, doubling the number of exposed will double the marginal cost. It is also important to include areas with relatively low noise levels if there is a large number of people living there. In our case study the areas with lower levels were more important than areas with high levels, as illustrated in Fig. 5.

The Environmental Noise Directive (European Commission 2002) required that all European road infrastructure managers reported the number of persons exposed to noise levels in $5 \mathrm{~dB}$ intervals of $L_{\mathrm{den}}$. The first set, which is for roads with more than 6 million vehicle passages and railroads with more than 60,000 train passages per year, was delivered during 2008. For details on the END calculation procedures see Hinton (2007). Using these data the total cost of noise along the reported road sections can be 
calculated, but to get the SRMC the marginal noise change must be calculated for the different vehicle types. The END data will only be available for roads with high traffic volumes though, and smaller roads should also be taken into account when designing a road charge system.

The most efficient way to calculate appropriate noise charges for larger areas (regions or nations) would, therefore, be to make detailed calculations for a number of representative areas and then extrapolate to whole regions. This extrapolation could be based on the assumption that the distribution of inhabitants in the larger areas are similar to the example areas used in the detailed analysis, and should then be corrected for traffic volume, road length through the area and the population density.

An example of very simple extrapolation is to base it on population density and road length through each sub area only. Our research area Lerum is part of the region Västra Götaland, and in Fig. 8 the situation is summarized for the ten municipalities north of Gothenburg that is part of the region and where E20 is passing through. Assuming that the distribution of inhabitants relative to the road is similar in all areas the marginal cost for one municipality can be calculated from the marginal cost in the reference area (Lerum) as

$$
m=m_{r e f} \frac{\sigma}{\sigma_{r e f}}\left(0.05 \frac{Q}{Q_{r e f}}+0.95\right),
$$

where $m$ is the marginal cost in $€ / \mathrm{km}, \sigma$ is the population density and $Q$ the traffic volume. Subscript ref denotes the same variables for the reference area. Units are not important as long as the same units are used in both areas. Note that a doubling of the population density doubles the marginal cost, but a doubling of the traffic flow only increase the marginal cost with about 5\%, which is in line with the analysis. The last part of equation 9 has been obtained by a linear regression over the interval 50-150\% of the dependence on traffic volume described in Fig. 7.

The resulting marginal cost for driving a heavy truck with 5 axles is presented in Table 3 , and is lowered from 0.012 to $0.0055 € / \mathrm{km}$ compared to only driving through Lerum. The same calculation can easily be repeated for the different vehicle classes and also using the $L_{\mathrm{DEN}}$ indicator, but is omitted here for brevity.

\section{DISCUSSION}

This study describes a method to estimate road-noise charges based on the marginal cost of a change in traffic volume. To demonstrate the estimation procedure and the feasibility of the method, we also estimated road-noise charges based on a Swedish case study. We advice against direct comparisons between the values for road traffic presented here and the railway values from our previous study (Andersson and Ögren 2007). Different values for the social cost of noise have been used in the two studies since the official Swedish values have been update since (Andersson and Ögren 2007) was published, and moreover, the relation between the two is only valid within the research area used in the case study.

The absolute values of the noise charges are of limited value, since they are based on a single case study, but the qualitative results have important policy implications 
Figure 8. Map outline over the municipalities used for extending the marginal cost estimation in Lerum to a larger region.

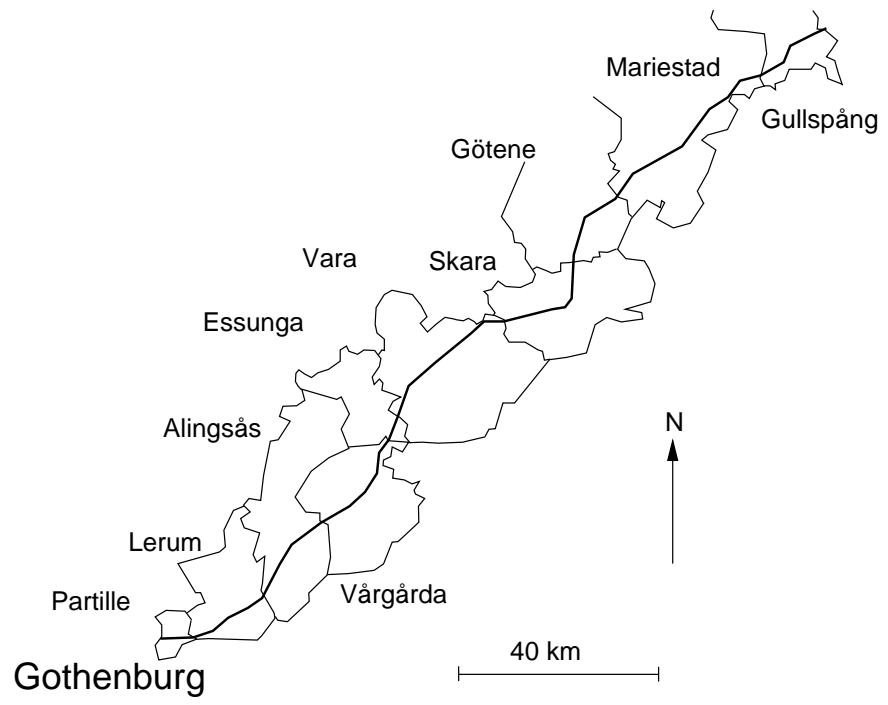

Table 3. Extending marginal cost calculation using inhabitant density and road length for a 5 axle heavy vehicle (class $3 \mathrm{c}$ )

\begin{tabular}{lrrrr} 
Municipality & $\begin{array}{r}\text { E20 length } \\
\text { km }\end{array}$ & $\begin{array}{r}\text { Pop. dens. } \\
\text { inh./km }\end{array}$ & $\begin{array}{r}\text { Traffic flow } \\
\text { veh./24h }\end{array}$ & $\begin{array}{r}\text { MC } \\
\in / \mathrm{km}\end{array}$ \\
\hline Partille & 8 & 591 & 29000 & 0.0741 \\
Lerum & 17 & 146 & 19000 & 0.0120 \\
Alingsås & 21 & 78 & 19000 & 0.0064 \\
Vårgårda & 23 & 26 & 11000 & 0.0012 \\
Essunga & 5 & 24 & 8000 & 0.0008 \\
Vara & 32 & 23 & 8000 & 0.0008 \\
Skara & 23 & 42 & 9000 & 0.0016 \\
Götene & 17 & 32 & 8000 & 0.0011 \\
Mariestad & 41 & 40 & 11000 & 0.0019 \\
Gullspång & 17 & 17 & 7000 & 0.0005 \\
\hline Total & 203 & & & 0.0055
\end{tabular}

since the case study shows that the SRMC: (i) is insensitive to changes in total traffic (within reasonable limits), (ii) is sensitive to the number of individuals exposed, and (iii) can be diversified according to vehicle type using standardized calculation methods. The first two findings suggest that policy makers generally can ignore changes in traffic volume but that it is important that the number of exposed individuals is accurate when noise charges for a specific road segment are estimated. The latter is especially relevant for individuals at lower noise levels, since most individuals belong to this group. Moreover, it also suggests that charges are sensitive to changes in the number of individuals exposed. However, generally this can be ignored since it is reasonable to assume that the number of exposed in the short run is fairly constant. 
An important aspect when designing a charging system is that it should be able to diversify between different vehicle types and technologies. A charge which is the same for all vehicles is an obvious problem, since it might destroy the incentive to drive more quite vehicles and/or to utilize technology that reduces the noise emission. As an example, changing to low noise tires on a truck can lower the noise emission by as much as $5 \mathrm{~dB}$ (Sandberg and Ejsmont 2002, ch. 20). Lowering the sound emission of the heavy truck with 5 axles (class $3 \mathrm{c}$ ) in our example by $5 \mathrm{~dB}$ lowers the marginal cost from $€ 0.012 / \mathrm{km}$ to $€ 0.0038 / \mathrm{km}$, a strong incentive to reduce noise if it is available within the road charge system. (Sandberg) shows that reducing tire noise is cost effective (Sandberg 2008, ch. 15).

We have shown that, with information on the number of people exposed, it is possible to calculate the SRMC for road noise by using standardized calculation methods and estimates of monetary values already in use by national authorities. The road noise prediction methods will be harmonized within the European Union in the future, and noise maps including information on the number of exposed inhabitants will be available for all major roads and cities as required by the Environmental Noise Directive of the European Commission (European Commission 2002). What remains before the SRMC can be determined is only to calculate the marginal change in the noise level for the different vehicle types under study, which can be done using either the relevant national noise calculation methods or Harmonoise.

\section{ACKNOWLEDGEMENTS}

The authors would like to express their gratitude to Evy Öhrström, Helena Svensson and Annbritt Skånberg for support with data. Financial support from Vinnova, Banverket, and the Swedish National Road Administration is gratefully acknowledged. The authors are solely responsible for the results presented and views expressed in this paper. 


\section{References}

Andersson, H. and Ögren, M. (2007). "Noise charges in rail infrastructure: A pricing schedule based on the marginal cost principle." Transport Policy, 14(3), 204-213.

Day, B., Bateman, I., and Lake, I. (2007). "Beyond implicit prices: Recovering theoretically consistent and transferable values for noise avoidance from a hedonic property price model." Environmental and Resource Economics, 37(1), 211-232.

de Vos, P. (2003). "How the money machine may help to reduce railway noise in $\mathrm{Eu}-$ rope." Journal of Sound and Vibration, 267(3), 439-445.

de Vos, P., Beuving, M., and Verheijen, E. (2005). "Harmonised accurate and reliable methods for the EU directive on the assessment and management of environmental noise - final technical report." Report no. http://www.harmonoise.org.

European Commission (1998). "White paper on fair pricing for transport infrastructure use."

European Commission (2001). "White paper - European transport policy for 2010: time to decide."

European Commission (2002). "Environmental noise directive 2002/49/EG."

Friberg, G., Bångman, G., Olsson, B., Ström, P., Jakobsson, H., Eriksson, G., Hjort, C., Nordlöf, P., von Koch, A., Björsell, M., Norberg-Schönfeldt, M., and Norman, P. (2008). "Samhällsekonomiska kalkylprinciper och kalkylvärden för transportsektorn." SIKA PM 2008:3, SIKA (Swedish Institute for Transport and Communications Analysis), Stockholm, Sweden.

Hinton, J. (2007). "Good practice guide for strategic noise mapping and the production of associated data on noise exposure." Position paper, European Commission Working Group Assessment of Exposure to Noise (WG-AEN). Version 2 (004.2007).

Jonasson, H. and Nielsen, H. (1996). "Road traffic noise - nordic prediction method." TemaNord 1996:525, Nordic Council of Ministers, Copenhagen, Denmark. ISBN 92-9120-836-1.

Nash, C. (2005). "Rail infrastructure charges in Europe." Journal of Transport Economics and Policy, 39(3), 259-278.

Navrud, S. (2004). "The economic value of noise within the european union - A review and analysis of studies." Mimeo.

Nelson, J. P. (2004). "Meta-analysis of airport noise and hedonic property values: Problems and prospects." Journal of Transport Economics and Policy, 38(1), 1-28.

Nijland, H. A., Van Kempen, E. E. M. M., Van Wee, G. P., and Jabben, J. (2003). "Costs and benefits of noise abatement measures." Transport Policy, 10(2), 131-140.

Nijland, H. A. and Van Wee, G. P. (2005). "Traffic noise in Europe: A comparison of calculation methods, noise indices and noise standards for road and railroad traffic in Europe." Transport Reviews, 25(5), 591-612.

Nota, R., Barelds, R., and van Maercke, D. (2005). "Harmonoise WP 3 engineering method for road traffic and railway noise after validation and fine-tuning." Report No. HAR32TR-040922-DGMR20.

Oertli, J. (2000). "Cost-benefit analysis in railway noise control." Journal of Sound and Vibration, 231(3), 505-509.

Öhrström, E., Barregård, L., Skånberg, A., Svensson, H., Ängerheim, P., Holmes, M., 
and Bonde, E. (2005). "Undersökning av hälsoeffekter av buller från vägtrafik, tåg och flyg i Lerums kommun." Report No. GU-MMED-R-2005/1-SE, Environmental Medicine, Sahlgrenska, Gothenburg, Sweden. ISSN 1400-5808.

Rothengatter, W. (2003). "How good is first best? marginal cost and other pricing principles for user charging in transport." Transport Policy, 10(2), 121-130.

Sandberg, U. (2008). "Economic incentives to encourage the use of consumer label for tyres in Europe." Final report 10 March 2008, European Federation for Transport and Environment (T\&E).

Sandberg, U. and Ejsmont, J. A. (2002). Tyre/Road Noise Reference Book. Informex, Kisa, Sweden. ISBN 91-631-2610-9.

Sansom, T., Nash, C. A., Mackie, P. J., Shires, J., and Watkiss, P. (2001). "Surface transport costs and charges: Great britain 1998." Final report, Institute for Transport Studies, University of Leeds, UK.

Wilhelmsson, M. (1997). "Trafikbuller och fastighetsvärden - en hedonisk prisstudie." Meddelande 5:45, Division of Building and Real Estate Economics, Royal Institute of Technology, Stockholm, Sweden. 